\title{
Tres reflexiones sobre la sociología de la literatura
}

María Belén Riveiro*

En 1984 la carrera de Letras de la Facultad de Filosofía y Letras de la Universidad de Buenos Aires (en adelante, UBA) abre el debate para la reformulación de su plan de estudios tras la intervención

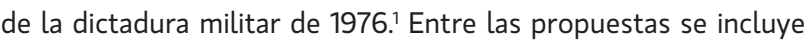
la de incorporar la materia Sociología de la literatura. Uno de los profesores de la carrera publica su opinión al respecto en el diario Clarín. El texto se titula "La cultura en peligro". El profesor es Jorge Luis Borges y se pregunta "¿Qué será la sociología de la literatura? El hecho estético es un brusco milagro. No puede ser previsto". 2

Lejos de la búsqueda de pronosticar hechos futuros, en este artículo argumentaré, en primer lugar, la vitalidad de reflexionar sobre la producción literaria desde la Sociología. En contraste con la postura de Borges, otros profesores de esa misma casa de estudios rescatan el desafío a los límites disciplinares y celebran los diálogos entre las Ciencias Sociales y la Crítica y la Teoría Literarias. En su reconstrucción de la carrera de Letras durante la transición democrática, Analía Gerbaudo identifica la productividad realizada en la zona de borde que debilita líneas de demarcación entre las disciplinas. ${ }^{3}$

Las Ciencias Sociales no se mantienen ajenas a estos debates. Eduardo Rinesi, quien proviene de la Ciencia Política y que

* Instituto de Investigaciones Gino Germani, Universidad de Buenos Aires y Consejo Nacional de Investigaciones Científicas y Técnicas. ORCID https://orcid.org/0000-0002-0499-9320.

1 Agradezco al director de mi beca posdoctoral, Lucas Rubinich, y a mi codirectora Daniela Lucena, por sus lecturas atentas y los constantes intercambios que mantenemos y que enriquecen mi trabajo. También querría dar mi agradecimiento a mi compañero de la cátedra Sociología general (Facultad de Ciencias Sociales - Universidad de Buenos Aires) Gustavo Moscona y a mi amiga y colega socióloga Guadalupe Seia, quienes leyeron, comentaron y recomendaron lecturas que, sin dudas, mejoraron el presente artículo.

2 Jorge Luis Borges. "La cultura en peligro", en Clarín, Buenos Aires, 13 de diciembre de 1984, p. 21.

3 Gerbaudo realiza una tarea de "exhumación" y halla transcripciones de clases. Una de ellas es la del seminario que dicta Josefina Ludmer en 1985 llamado Algunos problemas de teoría literaria. Ludmer inscribe la teoría literaria dentro de las Ciencias Sociales y propone: "Tenemos que explicitar eso: no somos una academia de Arte; no somos una facultad asocial. Estudiamos, precisamente, uno de los fenómenos fundamentales de la sociedad que es el lenguaje, el discurso, la cultura, la literatura", citado en Analía Gerbaudo, Políticas de exhumación. Las clases de los críticos en la universidad argentina de la posdictadura (1984-1986), Santa Fe, Buenos Aires, Ediciones de la Univeridad nacional del Litorial/ Ediciones de la UNiversidad Nacional de General Sarmiento, 2016, p. 52. actualmente dirige la Carrera de Especialización en Filosofía Política de la Universidad Nacional de General Sarmiento, participa del debate sobre la creación de la Facultad de Ciencias Sociales de la UBA en los años ochenta. El texto se publica en una revista santafesina dirigida por Horacio González, profesor de la por entonces naciente casa de estudios. Rinesi encuentra en la "transdisciplinariedad" una potencia desafiante:

La idea de "transdisciplinariedad" supone en cambio, me parece, la mucho más irreverente e interesante necesidad de resistir a que los saberes sean fragmentados, a que las necesidades de los feudalismos presupuestarios y administrativos devengan en feudalización misma del saber, a convertir a las formas de diagramar las fronteras entre las distintas "disciplinas" en simples funciones derivadas de los modos en que la organización burocrática de las oficinas públicas distribuye sus privilegios. ${ }^{4}$

En esta misma línea, en 2006 Aníbal Ford, profesor de la carrera de Letras, presenta una compilación de sus clases de los años setenta, 30 años después. 1973: las clases de introducción a la literatura y otros textos de la época (Ediciones de Periodismo y Comunicación, La Plata, 2005), en la Facultad de Ciencias Sociales (Imagen 1). En esas clases, cuando Letras compartía casa de estudios con la carrera de Sociología, es posible rastrear una sensibilidad sociológica para pensar la cultura y la literatura como producciones y discursos atravesados por la historia, las asimetrías y fenómenos sociales, políticos y económicos. ${ }^{5}$ En la

$4 \quad$ Eduardo Rinesi, “Ciencias Sociales: apuntes para una discusión”, en Cuadernos de la comuna, $n^{\circ} 15,1988$, p. 15.

5 Sensibilidad que se puede rastrear en su obra así como en su trayectoria. Las clases transcriptas en el libro mencionado son producto de su participación en la UBA cuando es convocado por el entonces director de la carrera de Letras, Francisco "Paco" Urondo. En los años sesenta y principios de los setenta, Ford trabaja en EUDEBA y el Centro Editor de América Latina, editoriales que desarrollan una mirada exegética sobre la tradición literaria nacional con una vocación de democratización de los criterios legítimos de valoración de la cultura literaria, así como de ampliación de públicos, tal como explica Hernán Vanoli en su tesis Por una sociología del espacio editorial: cuatro modelos de edición literaria en la Argentina del siglo XX, 2010. Ford es parte de la redacción de la revista Crisis y participa en La Opinión, El Porteño y Página/12. Después del retorno de la democracia, es el primer director de la carrera de Ciencias de la Comunicación (Facultad de Ciencias Sociales, Universidad de Buenos Aires), director de la Maestría en Comunicación y Cultura y docente titular de Teoría de la comunicación y Periodismo en esa casa de 
bibliografía de la materia se identifican autores centrales para la sociología como Karl Marx, Pierre Bourdieu y Antonio Gramsci junto con aportes de intelectuales que vitalizaron las discusiones tanto académicas como políticas de los años sesenta y setenta como Frantz Fanon y Arturo Jauretche.

Anclada en esta tradición, propongo discutir con la supuesta imposibilidad de construir explicaciones sociológicas para hechos como el literario. Cuando Émile Durkheim estudia la religión se encuentra con obstáculos similares que conciben a las creencias y a las manifestaciones religiosas como "desconcertantes" o dependientes de "una especie de aberración radical" a las que se les niega su realidad objetiva. ${ }^{6}$ Indagar en ellas lleva a concentrarse en creencias compartidas y a problematizar sentidos comunes. Mientras que la religión, con la creciente autoridad del conocimiento científico, sí se puede objetivar, el arte, que también gana en autonomía en la Modernidad, parece venir a ocupar un nueva autoridad espiritual difícil de asir en términos sociales e históricos. ${ }^{7}$ Su estudio desde la Sociología permite retomar problemáticas clásicas como las dicotomías entre lo individual y lo social o el texto y el contexto evitando esa "comodidad de la conjunción ' $y$ '", , que lejos de incorporar la teoría sociológica para construir lo literario como objeto une de manera acrítica dos categorías como política y poesía, economía y literatura, historia y ficción. Al tener como objetivo "ordenar conceptualmente la realidad empírica" es posible enfocarse en las relaciones. ${ }^{9}$

Una sociología que estudie objetos literarios, por un lado, posibilita el análisis de facetas sociológicas que enriquecen nuestro conocimiento sobre la producción de la literatura y de los libros. Guadalupe Maradei, que es Doctora en Letras, en sus investigaciones traza una lectura crítica de historias de la literatura argentina. ${ }^{10}$ Encuentra a fines de siglo $\mathrm{XX}$ y sobre todo a comienzos del XXI novedosos protocolos de lectura que historizan las prácticas literarias, reflexionan sobre los vínculos entre los textos y su recepción crítica, analizan sus condiciones de producción y conciben a los escritores como sujetos atravesados por múltiples condicionamientos. Esta sensibilidad sociológica de los protocolos permite formular interrogantes y aproximaciones críticas a la literatura escrita por mujeres. Ese

estudios y en la Universidad Nacional de La Plata.

6 Émile Durkheim, Las formas elementales de la vida religiosa, Buenos Aires, Editorial Schapire, 1968 [1912], p.8.

7 Lucas Rubinich; y Paula Miguel (eds.), 01 10, Creatividad, economía y cultura en la ciudad de Buenos Aires 2001-2010, Buenos Aires, Aurelia Rivera, 2011.

8 Jorge Panesi, "Política y ficción, o acerca del volverse literatura de cierta sociología argentina", en Boletín del grupo de estudios de teoría literaria, $n^{\circ}$ 4, abril de 1995, Rosario, p. 5.

9 Max Weber, Ensayos sobre metodología sociológica, Buenos Aires, Amorrortu editores, 1958, p. 47

10 Guadalupe Maradei, Contiendas en torno al canon. Las historias de la literatura argentina de posdictadura, Buenos Aires, Corregidor, 2020. mismo corpus, leído desde una mirada que desdeña su condición de producto social, reproduce esencias, estigmas y jerarquías que invisibilizan las particularidades de estos proyectos literarios. En tensión con las lecturas que restituyen las dicotomías que ubican a las escritoras del lado de lo irracional, lo pasivo y lo sensible, y a los escritores del lado de la política, la acción y la profesionalización, los protocolos que se formulan preguntas que podríamos calificar de sociológicas, como aquellas sobre las condiciones histórico-culturales de producción, leen en la literatura de mujeres rupturas frente a las prácticas de decoro, al sentimiento de pudor y a la posibilidad de experimentación de nuevos modos de vida. Por ejemplo, leen en Alfonsina Storni no una poesía cursi sino la inversión de los roles sexuales tradicionales y la ruptura con un registro de imágenes atribuidas convencionalmente a la mujer.

Me gustaría poder mencionar aquí algunas cuestiones referidas a mi propia experiencia de investigación en el marco de mis estudios doctorales. En mi tesis doctoral estudio la trayectoria de César Aira." Allí indago en dimensiones soslayadas del hecho literario como la trayectoria familiar y educativa del escritor, los espacios de sociabilidad por los que transita, la recepción de su obra, su trayectoria editorial y la carrera laboral, además de analizar su propia obra literaria. ${ }^{12}$ Construir un objeto desde la sociología me permite dar cuenta de la posibilidad de emergencia de un proyecto literario en su singularidad que, por lo menos en los años setenta, no parecía viable. Pensar estas hipótesis fue posible al implementar herramientas y estrategias metodológicas de la sociología, como entrevistas en profundidad, que permiten rescatar la dimensión subjetiva del hecho social, y el trabajo de archivo, que permite evitar la ilusión biográfica que proyecta de manera retrospectiva los sentidos comunes cristalizados. Esta última tarea también me permite rescatar, en particular, facetas de la obra de Aira que, al momento, no circulan, como su profusa participación en publicaciones periódicas, y centrarme en la materialidad de esa producción. ${ }^{13}$ También tomo como un

11 María Belén Riveiro, La trayectoria de César Aira: la conformación de un centro descentrado en el campo literario de la ciudad de Buenos Aires (1981-2001), Tesis doctoral, Facultad de Ciencias Sociales, Universidad de Buenos Aires, 2020.

12 Aira es un escritor argentino nacido en 1949 en Coronel Pringles, al sur de la provincia de Buenos Aires, quien, desde 1981 publica ensayos, obras de teatro y, en su mayoría, novelas. En 2018, su obra llega a superar los cien títulos. Para fines de los años noventa y comienzos del siglo XXI, rastreo indicadores convencionales de prestigio (cuenta con numerosos premios; es un autor muy traducido; ocupa un lugar central en editoriales; y su propuesta tiene una amplia recepción en la academia y en publicaciones periódicas como revistas literarias y suplementos culturales de diarios).

13 Durante el trabajo de archivo realizado pasé largas jornadas en diferentes instituciones. El trabajo allí y el acceso a las fuentes, vitales para la investigación, sólo fue posible por la ayuda de los bibliotecarios. Aprovecho esta oportunidad para reiterar mi agradecimiento al Centro de Documentación e Investigación de la Cultura de Izquierdas, la Biblioteca Prebisch del Banco Central de la República Argentina, la Hemeroteca de la Legislatura Porteña, la Biblioteca Nacional de Maestros, la Biblioteca de Literatura argentina de la Facultad de Filosofía y Letras de la Universidad de Buenos Aires, la Biblioteca del Congreso de la Nación, 
insumo más, claro, los aportes producidos por herramientas de la crítica literaria en la riqueza de su particularidad (sin pretender construir este tipo de conocimiento). Jorge Panesi defiende esta singularidad frente a una tendencia hacia la "des-literalización" o un volverse sociología de la crítica. ${ }^{14}$

Por el otro lado, la mirada sociológica sobre la producción literaria da cuenta de dimensiones y problemáticas soslayadas sobre lo social que se pueden vislumbrar al abordar estos temas. En la tesis doctoral mencionada adopto una mirada histórica y relacional que me permite reconstruir las distintas posiciones que ocupa Aira en el campo editorial y literario de Buenos Aires. Tras encontrar imágenes contrastantes como un completo rechazo de las editoriales en los años setenta hasta una creciente consagración a fines de los noventa y comienzos del siglo $\mathrm{XXI}$, defino un problema de investigación en torno a un tema central de la sociología como la dominación. ¿Cómo se vuelve Aira un centro del campo literario? ¿Qué características tiene? Se trata de un problema que cobra relevancia en relación con un eje alrededor del que giran las discusiones académicas respecto al mundo intelectual y artístico de fin de siglo cuando las centralidades y autoridades tradicionales se erosionan. ${ }^{15}$

Cuando Sarlo reflexiona sobre lo que denomina las consecuencias de la Sociología del arte y de las vanguardias artísticas identifica un mismo efecto, la desacralización del arte:

¿Qué queda de los conflictos cuando toda toma de partido estético es interpretada como búsqueda de legitimidad o de prestigio? ¿Qué queda de las elecciones cuando la libertad no es sino una ideología entre otras, a la cual se echa mano para disimular deseos menos inmateriales de consagración? ¿Qué queda de los valores estéticos cuando se asegura que son fichas de una apuesta en la mesa donde invariablemente

a Biblioteca Nacional Mariano Moreno, la Biblioteca Central de la Universidad de Rosario y la Biblioteca del Instituto de Investigaciones Gino Germani. Agradezco especialmente a Ignacio Mancini, bibliotecario de Instituto Germani, por estar siempre atento cuando necesité recursos bibliográficos. Parte de la documentación recabada me lleva a participar en la confección de anexos del libro que publica Ricardo Strafacce en Mansalva en 2018, César Aira, un catálogo, en el que enlista y selecciona una página de cada uno de los libros de Aira. En los anexos detallo los textos que salen en publicaciones periódicas. A su vez, se encuentra en prensa la publicación de parte de dicho corpus.

14 Define a la crítica literaria como un "acto de descolocación", es decir, de dispersar "el rumor inconfesado de lo que está produciéndose como un advenimiento sin nombre en el territorio social y en la babel de lenguas que exigen la escucha y el nombre", Jorge Panesi, op. cit., p.12.

15 Néstor García Canclini, Culturas híbridas, Estrategias para entrar y salir de la modernidad, México, Grijalbo, 1992 [1989]; Beatriz Sarlo, "Borges después de Borges", en Brigitte Adriaensen, Meike Botterweg Maarten Steenmeijer y Lies Wijnterp (eds.), Una profunda necesidad en la ficción contemporánea, la recepción de Borges en la república mundial de las letras, Madrid, Ediciones de Iberoamericana, pp. 31-44, 2015; Lucas Rubinich, "Prólogo", en Adrián Pulleiro, Liberales, populistas y heterodoxos, Estudios sobre intelectuales, cultura y política en la Argentina reciente, Buenos Aires, Batalla de ideas, 2017, pp. 13-18. se juega el monopolio de la legitimidad cultural? ${ }^{16}$

En la tesis propongo que quedan prácticas, creencias y valores y una realidad que podemos ordenar conceptualmente con las herramientas de la Sociología. Es posible pensarlas como acciones sociales condicionadas, síntesis de múltiples determinaciones, tal como las prácticas económicas, sociales, sindicales o políticas. A partir de ello, reconstruí los modos en que Aira se vuelve un centro, los efectos que ello supone en el campo y las particularidades de ese la autoridad que construye.

Retomando la idea de milagro — citada antes - de Borges, quiero volver a una de las reflexiones finales del libro sobre Mozart de Norbert Elias: "Wittgenstein dijo: 'De lo que no se puede hablar, mejor es callarse'. Yo creo que se podría decir con el mismo derecho: 'De lo que no se puede hablar, hay que investigar"'.17

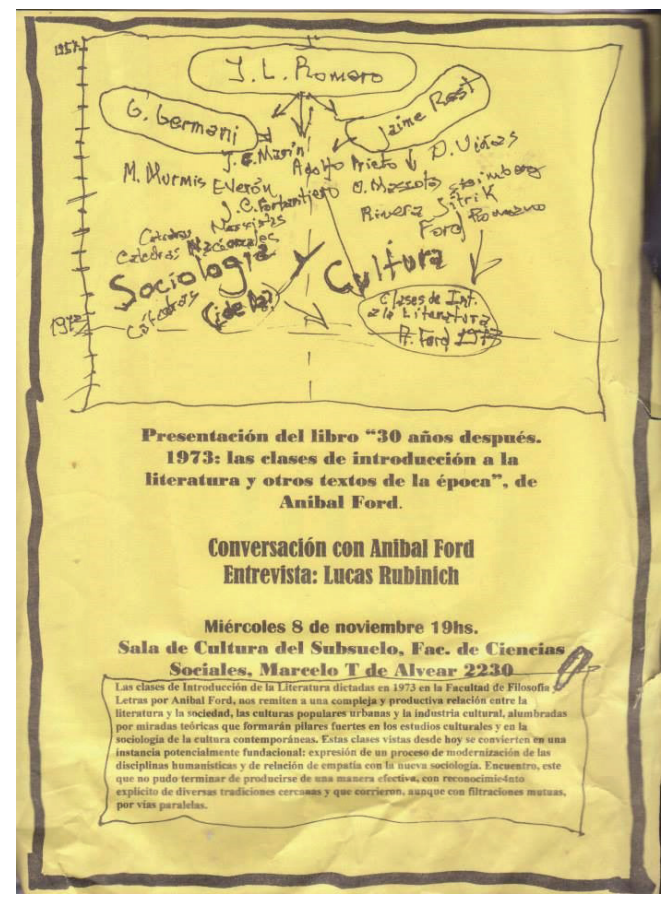

Imagen 1. Volante de la presentación del libro 30 años después. 1973: las clases de introducción a la literatura y otros textos de la época, de Aníbal Ford, realizada el 8 de noviembre de 2006. Facultad de Ciencias Sociales,

Universidad de Buenos Aires. Archivo personal de Lucas Rubinich.

\section{II}

16 Beatriz Sarlo, Escenas de la vida posmoderna, Intelectuales, arte y video-cultura en la Argentina, Buenos Aires, Ariel, 1994, p. 82.

17 Norbert Elias, Mozart. Sociología de un genio, Barcelona, Editorial Península, 1991, p. 154 
Es posible identificar recientes indicadores de la conformación de un campo de estudios que se puede denominar Sociología de la literatura. Recopilo algunos de ellos. Desde 2013, Mariana Cerviño dicta la materia Sociología del Arte. Producción y Circulación de Artes Visuales y Literatura en Argentina en la carrera de grado de Sociología de la Facultad de Ciencias Sociales (UBA). En 2018 Soledad Quereilhac da el seminario La sociología de la literatura: perspectivas teóricas y propuestas metodológicas en la Maestría en Sociología de la Cultura y Análisis Cultural (Instituto de Altos Estudios Sociales). En 2020 Hernán Maltz dicta Sociologías de la literatura policial en la carrera de grado de Letras (Facultad de Filosofía y Letras, UBA) y Sociologías de la literatura en el Doctorado en Ciencias Sociales (Facultad de Ciencias Sociales, UBA).

En 2017, el Fondo de Cultura Económica traduce el libro Sociología de la literatura de Gisèle Sapiro, un trabajo programático que traza una historia de este conjunto de estudios. Además, la autora viaja a Buenos Aires para la presentación del libro en la Librería del Fondo Arnaldo Orfila Reynal a cargo de Soledad Quereilhac y Alejandro Blanco en octubre de ese mismo año. De manera contemporánea, la revista Apuntes de investigación del CECYP incluye estudios que sistematizan tradiciones cercanas como las de la sociología del arte, ${ }^{18}$ y los estudios sociológicos abocados a la literatura desde una perspectiva transnacional. ${ }^{19}$

¿Podemos afirmar la existencia de un ámbito de estudios específico llamado Sociología de la literatura? En lugar de discutir sobre cómo definir este ámbito, propongo reflexionar de manera crítica sobre el supuesto de las divisiones en sub-disciplinas o especializaciones. Distinguir ámbitos de estudio dentro de una misma ciencia por temáticas puede tener fines pragmáticos, de discusión e intercambio de hallazgos. Sin embargo, los problemas sociales, las divisiones que operan en la cotidianeidad o el recorte de un objeto de investigación no se puede definir como problema sociológico por sí solo sino en relación con una "problemática teórica que permita someter a un sistemático examen todos los aspectos de la realidad puestos en relación por los problemas que le son planteados". 20

A modo de ilustración, en mi tesis mientras trabajo sobre la producción literaria argentina retomo aportes de distintas producciones sociológicas. Reconstruyo la trayectoria familiar y educativa de Aira para dar cuenta de los capitales, conocimientos

18 Daniela Lucena, "Sociología del arte, Un mapa posible de su desarrollo en Argentina", en Apuntes de Investigación del CECYP, $n^{\circ}$ 30, 2018, pp. 151-160. Disponible en http.//apuntescecyp.com.ar/index.php/apuntes/ article/view/687/532.

19 Mariana Cerviño, "El estudio de la literatura y el arte en las "periferias", Algunos aportes de la perspectiva transnacional", en Apuntes de Investigación del CECYP, $n^{\circ}$ 30, 2018, pp. 161-170. Disponible en http.// apuntescecyp.com.ar/index.php/apuntes/article/view/688/528.

20 Pierre Bourdieu, Jean-Claude Chamboredon, y Jean-Claude Passeron, El oficio del sociólogo, Buenos Aires, Siglo XXI, 2002 [1973], p. 54. y valores que tiene incorporados al ingresar al campo literario. Me nutro de investigaciones como aquellas centradas en la inmigración histórica que permiten vislumbrar las trayectorias de segundas y terceras generaciones, como la del propio Aira, así como la movilidad social ascendente de algunos sectores que conforman una clase media que valora, en particular, el consumo cultural. ¿Cómo distinguir estas problemáticas? ¿Sociología de la literatura o Sociología de la inmigración? ¿Sociología de la clase media o de la movilidad social ascendente? ¿Cómo afectan estas inscripciones en la formulación de preguntas de investigación?

Más allá de las críticas teóricas a este modo de concebir la Sociología, la noción de especialización o sub-disciplina es, sin duda, efectiva y también es posible rastrear su historia. En Argentina, en particular, el retorno de la democracia abre discusiones sobre la reconstitución de instituciones de enseñanza e investigación que, más tarde, experimentarán las transformaciones neoliberales. ${ }^{21}$ La profesionalización de la investigación, que habilita la inserción académica de intelectuales y la apertura del sistema de posgrados, lleva a consecuencias no deseadas como "una serie de procesos burocratizados, rutinarios, que fragmentan el conocimiento y lo despojan de compromiso político o transformador".22

Definida en contraposición al "intelectual público", aparece la figura del "investigador científico", cuya carrera se profesionaliza a la par que las problemáticas privilegiadas por estudiar se alejan de los temas y la agenda pública. ${ }^{23}$ Este "ensimismamiento" se expresa como segmentación o especialización de subcampos de estudio. ${ }^{24}$ Dicha delimitación de objetos permite la internacionalización de los estudios, que aleja las investigaciones de las agendas de cada país, las distancia de los debates públicos y lleva al abandono de los "grandes problemas". 25

Los efectos incluso se rastrean en las trayectorias de investigadores dominadas por una carrera signada por la competencia y enfocada en acreditar saberes. ${ }^{26}$ Estudiosos analizaron las consecuencias de los modos de evaluación como

21 Lucas Rubinich, La conformación de un clima cultural. Neoliberalismo y universidad, Buenos Aires, Libros del Rojas, 2001.

22 Martín Unzué, Profesores, científicos e intelectuales, La Universidad de Buenos Aires de $\mathbf{1 9 5 5}$ a su Bicentenario, Buenos Aires, Instituto de Investigaciones Gino Germani y CLACSO, 2020, p. 164.

23 Pablo Kreimer y Alejandro Blanco, "Sociologie et démocratie? Un panorama de la discipline en Argentine entre 1983 et 2007", en Sociologies pratiques, $n^{\circ} 16$, Vol.1, 2008, pp. 147-161.

24 Juan Pedro Blois, "El mercado de trabajo de los sociólogos en Argentina desde la vuelta de la democracia. El caso de los graduados de la UBA", en Trabajo y Sociedad, $n^{\circ} 22,2014$, p. 106. Disponible en http.//www. redalyc.org/articulo.oa?id=387334694008.

25 Pablo Kreimer y Alejandro Blanco, op. cit., p. 159.

26 Monica Marquina, Jose Yuni, y Mariela Ferreiro, "Generational change in the Argentine academic profession through the analysis of 'life courses"' en Studies in Higher Education, $n^{\circ}$ 8, Vol. 40, 2015, pp. 1392-1405. Disponible en http.//dx.doi.org/10.1080/03075079.2015.1060707 
el sistema de referato de las revistas científicas que, tal como funciona, suele llevar a la "formación de grupos monolíticos, que desarrollan modelos hegemónicos para su pequeña parcela del saber" que empobrece la producción de conocimiento en tanto allí "difícilmente se lea algo diferente al modelo aceptado". ${ }^{27}$

En medio de estas condiciones de producción de conocimiento resulta sugerente volver a la historia de la Sociología argentina que pocos años antes, en fuerte contraste con este panorama, afirmaba que sus temas y problemas "son básicos, esenciales (...) y adquieren un carácter moral impuesto por la realidad del país y del TERCER MUNDO". ${ }^{28}$ Claro que es preciso repensar estas posiciones ante los "reacomodamientos estructurales y simbólicos" de fin de siglo que suponen un desajuste entre la tradición del sociólogo intelectual, una "experiencia histórica que aparece desvalorizada", y "sensibilidades y formas de organización del mundo social y cultural que no se corresponden con esa experiencia". ${ }^{29}$

Propongo rescatar la necesidad de reflexionar sobre nuestras condiciones de producción y nuestros modos de vincularnos con la práctica científica en tanto, y eso nos enseña Roberto Carri en los años sesenta, "las concepciones de la ciencia no tienen autonomía real, se subordinan a un orden o práctica social y política, más allá de la buena o mala voluntad del investigador".$^{30}$ Y así retomar nuestra tradición de sociólogos argentinos que se definen a partir de "lo que la tradición occidental del último siglo conoce como intelectuales" con una "vocación de intervención pública" entendida como

la pertenencia simbólicamente significativa a tradiciones culturales distintas pero que trascienden la actividad académica, la confianza en las herramientas académico culturales como elemento favorecedor de transformaciones sociales y la consecuente vocación de intervención pública. ${ }^{31}$

27 Ana Lía Kornblit, "De referatos, referees y jueves", en Sociedad, Revista de la Facultad de Ciencias Sociales de la UBA, $n^{\circ} 22$, primavera de 2003 , p. 254, Disponible en http.//www.sociales.uba.ar/wp-content/ uploads/Sociedad_22.pdf.

28 Enrique Pecoraro, "La sociología nacional, las sociologías y la sociología", en Antropología, 3er mundo, Revista de ciencias sociales, $n^{\circ} 2$, Vol. 5 , 1972, p.79.

29 Lucas Rubinich, "Las voces de los intelectuales. Hay molinos y hay gigantes", en Todavía. Pensamiento y cultura en América Latina, $n^{\circ} 27$, mayo de 2012, p. 24

30 Roberto Carri, Isidro Velázquez, Formas prerrevolucionarias de la violencia, Buenos Aires, Colihue, 2001 [1968], p. 103.

31 Lucas Rubinich, "Los sociólogos intelectuales, cuatro notas sobre la sociología en los años 1960", en Apuntes de Investigación del CECYP, $n^{\circ}$ 4, Vol. 3, junio de 1999, p. 33.
III

En este último punto reflexiono sobre un conjunto de estudios que formula problemas sociológicos relativos a lo literario. Son parte de una historia heterogénea y no tan reciente de análisis de temas literarios que se propone formular problemas de investigación relevantes a la Sociología como ciencia sin restringirse a su estudio "por el solo placer de relatar sus extravagancias y singularidades". 32

Encuentro que un primer conjunto de estudios se centra en el análisis de diversos estados del campo literario. En Argentina, entre los introductores de Bourdieu a los estudios del arte y la literatura se encuentran Beatriz Sarlo y Carlos Altamirano. ${ }^{33}$ Sus primeras producciones son artículos publicados a principios de los años ochenta en revistas especializadas del exterior dado que el mercado editorial se había visto restringido y censurado durante la dictadura cívico militar entre 1976 y 1983. En esos años la reflexión sobre la literatura les permite indagar en cuestiones sociales sobre las que no se podía escribir sin mediaciones y vitalizar el trabajo intelectual evitando "el fetichismo de los conceptos". ${ }^{34}$ Estas indagaciones no sólo permiten plantear sugerentes problemas, como la concepción del surgimiento de una vanguardia artística a principios del siglo $X X$ poco cuestionadora del orden social aunque trasformadora de costumbres literarias a diferencia de las vanguardias europeas, sino también repensar de manera crítica las nociones teóricas. A modo de ilustración, Sarlo problematiza y se aleja de la noción cristalizada de la relación periferia y centro como una de copia y reproducción irreflexiva.

Dentro de este mismo conjunto de estudios podemos incluir la investigación de Claudia Gilman sobre la producción literaria e intelectual latinoamericana de los sesenta y setenta y los vínculos entre literatura y política; ${ }^{35}$ el valioso aporte de José Luis de Diego, quien realiza un exhaustivo estudio del campo intelectual y literario de los años setenta y ochenta para pensar las transformaciones en las producciones durante la dictadura militar y la transición democrática; ${ }^{36}$ la compilación a cargo de Susana Rodríguez sobre el campo cultural de Salta entre las décadas de los años sesenta y setenta a partir de los debates y

32 Émile Durkheim, op. cit., p. 7.

33 Ana Teresa Martínez, Pierre Bourdieu, razones y lecciones de una práctica sociológica, Del estructuralismo genético a la sociología reflexiva, Buenos Aires, Manantial, 2007.

34 Carlos Altamirano, y Beatriz Sarlo, Ensayos argentinos. De Sarmiento a la vanguardia, Buenos Aires, Ariel, 1997, p. 12.

35 Claudia Gilman, Entre la pluma y el fusil, Debates y dilemas del escritor revolucionario en América Latina, Buenos Aires, Siglo XXI, 2003.

36 José Luis de Diego, ¿Quién de nosotros escribirá el Facundo? Intelectuales y escritores en Argentina (1970-1986), La Plata, Ediciones al margen, 2007. 
producciones periodísticas y literarias; ${ }^{37}$ la cartografía del campo literario de Buenos Aires que traza Ariel Idez concentrándose en las revistas Literal y Sitio; ${ }^{38}$ la investigación de Soledad Martínez Zuccardi centrada en publicaciones periódicas que le permite preguntarse por la conformación del campo literario e intelectual tucumano a principios del siglo pasado; ${ }^{39}$ y la reconstrucción de ciertas zonas y debates del campo intelectual argentino de fines del siglo $X X$ y principios del siglo XXI que realiza Adrián Pulleiro. ${ }^{40}$

Un segundo conjunto de estudios puede agruparse en relación con aquellos aportes enfocados en la dimensión de los lectores. Para ello resulta vital Sociología del público argentino de Adolfo Prieto. Publicado en 1956, este libro parte de un diagnóstico de los propios escritores que argumentan que no tienen lectores y su hipótesis acerca de que los escritores tienen un espíritu que recuerda a los gremios de la Edad Media que los enclaustra. Prieto se pregunta ¿cómo está conformado el público que lee literatura argentina ${ }^{31}$ No resulta sorprendente que para responder parte de este interrogante y para fundamentar la hipótesis de la existencia de un público lector minoritario de literatura argentina recurra a datos estadísticos como los que produce Gino Germani en su investigación sobre la clase media. ${ }^{42}$

Investigaciones dentro de esta misma línea definen como objetivo caracterizar al público lector y rastrear circuitos de lectura. Lucas Rubinich aboca su tesis al estudio de un libro definido como clásico, como el Martín Fierro, en el período anterior a recibir esa consagración. ${ }^{43}$ Prieto analiza los sectores del país y

37 Susana, A. C. Rodríguez (coord.), Periodismo y literatura. El campo cultural salteño del '60 al 2000, Salta, Universidad de Salta, 2007.

38 Ariel Idez, La revista Sitio y las figuras del intelectual sobre el fin de la dictadura, Tesis de maestría, Facultad de Ciencias Sociales, Universidad de Buenos Aires, Buenos Aires, 2017; Ariel Idez, Literal, La vanguardia intrigante, Buenos Aires, Prometeo libros, 2010.

39 Soledad Martínez Zuccardi, En busca de un campo cultura propio, Literatura, vida intelectual y revistas culturales en Tucumán (1904-1944), Buenos Aires, Corregidor, 2012.

40 Adrián Pulleiro, Liberales, populistas y heterodoxos, Estudios sobre intelectuales, cultura y política en la Argentina reciente, Buenos Aires, Batalla de ideas, 2017.

41 Adolfo Prieto, Sociología del público argentino, Buenos Aires, Ediciones Leviatán, 1956.

42 En 1943 Germani organiza, junto con estudiantes del Instituto de Sociología de la Facultad de Filosofía y Letras de la UBA, una encuesta sobre actividades culturales y deportivas. En tanto reconoce un criterio psicosocial como relevante para el estudio de las clases indaga en los consumos culturales y el empleo de las horas libres. Los resultados se publican en 1950 con el título "La clase media en la Argentina con especial referencia a sus sectores urbanos". El cuestionario que elaboran se realiza de manera presencial y dura 40 minutos aproximadamente. Se elige a los entrevistados de acuerdo al grupo profesional al que pertenecen (en tanto se toma esta característica como indicador de pertenencia a la clase media). Las entrevistas se realizan en clubes, asociaciones y oficinas administrativas.

43 Lucas Rubinich, Indiferencia del público lector de la ciudad de Buenos Aires ante el éxito editorial del Martín Fierro (1873-78), Tesis de posgrado, Facultad de Ciencias Sociales, Universidad de Buenos Aires, Buenos Aires, 1982. los modos y las prácticas de lectura del Martín Fierro, así como de otras obras y de otros folletines gauchescos.44 Fabio Espósito revisita estas cuestiones en relación con la conformación de la novela en Argentina a fines del siglo XIX. ${ }^{45}$ También contamos con etnografías de lectura que se preguntan por los modos de apropiación de los lectores como aquellos de un best seller como los libros de Paulo Coelho, ${ }^{46}$ y por las experiencias de lectura enfocadas en un público juvenil e infantil que confrontan el sentido común que sostiene que los jóvenes no leen. ${ }^{47}$ Otros estudios indagan en los modos en que se representa y se construye a un tipo de lector dentro de la misma ficción, ${ }^{48}$ desde editoriales ${ }^{49} \mathrm{y}$ desde las bibliotecas. ${ }^{50}$

Contamos con investigaciones que suman la dimensión estadística para estudiar el público lector alineados a la tradición de Prieto y Germani. Ana Wortman se pregunta por la transformación de las clases medias de principios del siglo XXI y por la resignificación de sus consumos, uno de los cuales es el de libros. ${ }^{51}$ Ezequiel Saferstein realiza un primer análisis de los datos resultantes de la primera encuesta sobre hábitos de lectura en la Feria de editores de $2018 .^{52}$

44 Adolfo Prieto, El discurso criollista en la formación de la Argentina moderna, Buenos Aires, Sudamericana, 1988.

45 Fabio Espósito, La emergencia de la novela en Argentina, La prensa, los lectores y la ciudad (1880-1890), La Plata, Ediciones al margen, 2009.

46 Pablo Semán, Bajo continuo, Exploraciones descentradas sobre cultura popular y masiva, Buenos Aires, Editorial Gorla, 2006.

47 Giuliana Pates, "¿Los/as jóvenes no leen? Experiencias de lecturas en booktubers", en Letras, $n^{\circ} 1,2015$. Disponible en http.//sedici.unlp.edu.ar/ bitstream/handle/10915/46664/Documento_completo.pdf?sequence=1; Paula Cuestas, "'Potterheads y feministas', Experiencias de politización y militancia de lectoras de Harry Potter al calor del debate por la IVE", en El toldo de Astier, $n^{\circ}$ 17, Vol. 9, 2016, pp.44-53; Paloma Sánchez, Nuevas formas de apropiación cultural juvenil, Representaciones sobre los procesos de lectura y escritura en soportes digitales, Tesis doctoral, Facultad de periodismo y comunicación social, Universidad Nacional de La Plata, 2018. Disponible en http://sedici.unlp.edu.ar/ handle/10915/74969; Victoria Saez, "De las pantallas al papel, Nuevos acercamientos de los jóvenes a la literatura", en El toldo de Astier, $\mathrm{n}^{\circ}$ 18, Vol. 10, 2019, pp. 42-51.

48 Emilio Carilla, "Autores, libros y lectores en la literatura argentina", en Cuadernos de Humanitas, $n^{\circ} 51$, Facultad de Filosofía y Letras, Universidad Nacional de Tucumán, 1979; Susana Zanetti, La dorada garra de la lectura, Lectores y lectoras de novela en América Latina, Rosario, Beatriz Viterbo Editora, 2002; Graciela Batticuore, La Mujer Romántica, Lectoras, Autoras y Escritores En La Argentina, 1830-1870, Buenos Aires, Edhasa, 2005

49 Magdalena Cámpora, "Una tradición para el lector argentino, Ediciones populares de clásicos franceses, décadas del treinta y del cuarenta", en El taco en la brea, $n^{\circ}$ 5, Vol. 4, 2017, pp. 322-344.

50 Javier Planas, Libros, lectores y sociabilidades de lectura, Una historia de los orígenes de las bibliotecas populares en la Argentina, Buenos Aires, Ampersand, 2017.

51 Ana Wortman, "Consumos de las nuevas clases medias, fragmentación de públicos en la Argentina contemporánea, Una mirada a partir de los libros", Actas del Primer Coloquio Argentino de Estudios sobre el Libro y la Edición, La Plata, Facultad de Humanidades y Ciencias de la Educación, Universidad Nacional de La Plata, 2012, pp. 563-575. Disponible en http://coloquiolibroyedicion.fahce.unlp.edu.ar/actas/Wortman.pdf/ view?searchterm=Non.

52 Ezequiel Saferstein, "Las ferias de libros y sus públicos Circulación, visibilidad y desigualdades estructurales en el campo editorial", en Daniel Ba- 
Un tercer grupo de investigaciones se concentra en las editoriales como la tesis de maestría de Hernán Vanoli que historiza el mundo editorial argentino del siglo XX a través de cuatro modelos editoriales para preguntarse por el lugar socialmente asignado a lo literario, por la circulación social de la fe en la literatura, por el vínculo de las editoriales con la literatura argentina y por la posibilidad de formación de ciudadanías culturales. ${ }^{53}$ En esta misma línea de preguntas, de Diego compila trabajos sobre el mundo editorial y su historia en Argentina. ${ }^{54}$ María Fernández Moya estudia el proceso de transnacionalización y concentración de las editoriales para el caso europeo. ${ }^{55}$ Ezequiel Saferstein se concentra en la transformación del rol del editor tras el proceso de extranjerización de las editoriales a partir de la conceptualización de un sentido práctico. ${ }^{56}$ Daniela Szpilbarg describe el campo editorial argentino de fines de la década de los años noventa y comienzos del siglo XXI, construye una tipología de editores e indaga en la circulación de la producción editorial nacional en el espacio internacional. ${ }^{57}$ Matías Moscardi analiza las "editoriales interdependientes" argentinas de los años noventa del siglo XX enfocado en la relación entre prácticas de edición y prácticas poéticas. ${ }^{58}$

En cuarto lugar, contamos con investigaciones que estudian las producciones editoriales y literarias desde una perspectiva de género en tanto estudiosos han reparado que se trata de un

denes y Verónica Stedile Lina (comps.), Estado de feria permanente, La experiencia de las editoriales independientes argentinas 2001-2020 La Plata, Club Hem, 2019.

53 Hernán Vanoli, Por una Sociología del espacio editorial cuatro modelos de edición literaria en la Argentina del siglo XX. Tesis de maestría, Facultad de Ciencias Sociales, Universidad de Buenos Aires, 2010. De manera más reciente, revisa esta misma escena, es decir, la literatura como vínculo problemático con otros discursos y visiones y como herramienta para la construcción de ciudadanías de consumo ahora a través del estudio de las condiciones de producción, circulación y recepción de la literatura en medio de una contemporaneidad dominada por lógicas de procesamiento algorítmico de los datos. Propone que vitalizar la literatura no se restringe a renovar textos ni a incorporar nuevas voces o temas sino a una reformulación de los vínculos entre las plataformas de datos, el mercado y la política. Ver Hernán Vanoli, El amor por la literatura en tiempos de algoritmos. 11 hipótesis para discutir con escritores, editores, lectores, gestores y demás militantes, Buenos Aires Siglo XXI y Crisis, 2019.

54 José Luis de Diego (dir.), Editores y políticas editoriales en Argentina (1880-2010), Buenos Aires, Fondo de Cultura Económica, 2014 [2006].

55 María Fernández Moya, "La internacionalización del sector editorial es pañol (1898-2010)", X Congreso Internacional de la Asociación Española de Historia Económica, Sevilla, Universidad Pablo de Olavide Carmona, 2011.

56 Ezequiel Saferstein, "El "sentido práctico del editor", transformaciones y tensiones en el transformaciones y tensiones en el rol del Director Editorial de las grandes empresas en Argentina", en Prácticas de oficio, Investigación y reflexión en Ciencias Sociales, $n^{\circ}$ 14, 2014. Disponible en https.//ides.org.ar/publicaciones/practicasdeoficio/practicas-deoficio-investigacion-y-reflexion-en-ciencias-sociales-nro-14.

57 Daniela Szpilbarg, Cartografía argentina de la edición mundializada, Modos de hacer y pensar el libro en el siglo XXI, Buenos Aires, Tren en movimiento, 2019.

58 Matías Moscardi, La máquina de hacer libritos, Poesía argentina editoriales interdependientes en la década de los noventa, Córdoba, Editorial Universitaria Villa María, 2019 espacio dominando por la lógica masculina. ${ }^{59}$ Simone Murray estudia editoriales feministas británicas. ${ }^{60}$ Ello le permite analizar las tensiones entre un mundo como el editorial, dominado por la lógica masculina y las prácticas de mujeres. Ese mismo vínculo conflictivo lo define en relación con la resistencia a la lógica capitalista a la que se opone el movimiento feminista y la participación en el mercado editorial que sigue esas mismas reglas. A través del análisis empírico también entabla una discusión sobre el modelo para estudiar la historia del libro propuesta por Robert Darnton. Incluir la variable de género no sólo supone llenar vacíos en la historia sino reconceptualizar la disciplina.

De manera reciente, se encuentra que el caso argentino no es una excepción a la dominación de la lógica masculina en la producción editorial. ${ }^{61}$ Cada vez más investigaciones reconstruyen trayectorias y visibilizan casos particulares de editoras. ${ }^{62}$ Para el caso argentino, comienzan a formularse preguntas por las contribuciones de las mujeres en los espacios editoriales, ${ }^{63}$ y por cómo construir una historia de las editoriales atravesada por el género y el feminismo. ${ }^{64}$

En quinto lugar, una serie de análisis incorporan la dimensión internacional. Brigitte Adriaensen, Meike Botterweg, Maarten Steenmeijer y Lies Wijnterp compilan un libro sobre la recepción de Jorge Luis Borges en la república mundial de las letras entre los que se encuentra un texto de Sarlo que estudia los modos en que cobra relevancia a nivel internacional la obra de Borges y sus efectos. ${ }^{65}$ Esto le permite hipotetizar los modos en que Borges ocupa un espacio central, una posición que "es imposible

59 Leslie Howsam, "In My View, Women and Book History", en SHARP News, $n^{\circ} 4$, Vol. 7, 1998, pp. 1-2. Disponible en https://scholarworks, umass,edu/sharp_news/vol7/iss4/1.

60 Simone Murray, Mixed Media, Feminist Presses and Publishing Politics, Londres y Virginia, Pluto Press, 2004.

61 Ivana Mihal, Ana Elisa Ribeiro y Daniela Szpilbarg (coords.), "Dossier, Editoras y autorías, las mujeres en el mundo editorial latinoamericano", en Cuadernos del Centro de Estudios en Diseño y Comunicación, $n^{\circ}$ 107, 2020. Disponible en https://fido.palermo.edu/servicios_dyc/ publicacionesdc/cuadernos/detalle_publicacion.php?id_libro=835.

62 Pura Fernández, “¿Una empresa de mujeres? Editoras iberoamericanas contemporáneas", en Lectora, $n^{\circ} 25,2019$, pp. 11-39. Disponible en https// revistes.ub.edu/index.php/lectora/article/view/29830; Ana Elisa Ribeiro, "Editoriales y editoras en Brasil hoy. Dos casos contemporáneos: Chão da feira y Relicário", en Lectora, n²5, 2019, pp.227-240. Disponible en https//revistes.ub.edu/index.php/lectora/article/view/29843/0.

63 Marcela Castro, "Dossier, Mujeres que hacen libros", en Mora, n², Vol 7, septiembre de 2011. Disponible en http://www.scielo.org.ar/scielo. php?script=sci_issuetoc\&pid=1853-001X20110002\&lng=es\&nrm=iso.

64 Daniela Szpilbarg, "Armas cargadas de futuro, hacia una historia feminista de la edición en Argentina", en Malisia. La revista, $n^{\circ}$ 4, Vol. 1, mayo de 2018, 2018, pp. 15-29; Viviana Román, y María Cristina Spadaro, "Mujeres en la historia de la edición argentina. ¿La edición va teniendo marca de género?", en La aljaba, segunda época, n²3, 2019, pp. 169-189.

65 Brigitte Adriaensen, Meike Botterweg, Maarten Steenmeijer y Lies Wijnterp (eds.), Una profunda necesidad en la ficción contemporánea: la recepción de Borges en la república mundial de las letras, Madrid, Ediciones de Iberoamericana, 2015. 
de ocupar" con posterioridad. ${ }^{66}$

Contamos con estudios producidos desde América Latina sobre los vínculos entre la literatura latinoamericana, y argentina en particular, y el plano internacional, así como con reflexiones sobre las relaciones problemáticas entre los centros y las periferias. ${ }^{67}$ Para estudiar los vínculos entre el campo de origen y el campo de llegada de las producciones literarias, las investigaciones reparan en mediadores como los propios escritores y la circulación de sus libros en el plano internacional, ${ }^{68}$ agentes literarios ${ }^{69}$ y traductores. ${ }^{70}$

Cierro con un sexto grupo de investigaciones producidas desde y sobre América Latina. En 1977 Sergio Miceli publica en Brasil un estudio sobre la conformación del campo intelectual brasileño que aparece dos años antes en la revista Actes de la recherche en sciences sociales ("Division du travail entre les sexes et division du travail de domination [une étude clinique des anatoliens au Brésil"]). Miceli toma la periodización de la historia de la literatura brasileña confeccionada por la crítica y se detiene en el "premodernismo" que, advierte, adquiere esa categoría por la dominación del modernismo posterior con cuya autoridad estética reduce a los intelectuales que los preceden en el tiempo a sus antecesores. A partir de ello Miceli se concentra en ese período porque, hipotetiza, es cuando se construyeron las condiciones de posibilidad para la profesionalización del trabajo intelectual y literario y para la autonomía del campo. También realiza estudios comparativos sobre los campos literarios de los

66 Beatriz Sarlo, op. cit., 2015, p. 41.

67 Jorge Schwartz, Vanguardia y cosmopolitismo en la década del veinte, Oliverio Girondo y Oswald de Andrade, Rosario, Beatriz Viterbo, 2002 [1983]; Ángel Rama, Transculturación narrativa en América Latina, Buenos Aires, Ediciones El andariego, 2008 [1984]; Alejandro Losada, "La Internacionalización de la literatura latinoamericana", en Cahiers du monde hispanique et luso-brésilien, Littérature et Société en Amérique latine, $\mathrm{n}^{\circ} 42,1984$, pp. 15-40. Disponible en https:// www,persee,fr/doc/carav_0008-0152_1984_num_42_1_1666; María Teresa Gramuglio, Nacionalismo y cosmopolitismo en la literatura argentina, Rosario, Editorial Municipal de Rosario, 2013.

68 Héctor Hoyos, Beyond Bolaño. The Global Latin American Novel, Nueva York, Columbia University Press, 2015.

69 Jorge Locane, 'La mediación oculta, los agentes literarios en la producción de literatura 'latinoamericana' en Europa', en Iberoromania, Revista dedicada a las lenguas, literaturas y culturas de la Península Ibérica y de América Latina, $n^{\circ} 85,2017$, pp. 47-57.

70 Gustavo Sorá, Traducir El Brasil, una antropología de la circulación internacional de ideas, Buenos Aires, Libros del Zorzal, 2003; Patricia Willson, La Constelación del Sur, Traductores y traducciones en la literatura argentina del siglo XX, Buenos Aires, Siglo XXI, 2004; Gabriela Adamo (comp.), La traducción en América Latina, Buenos Aires, Paidós, 2012; Alejandrina Falcón, Exilio y traducción, importadores argentinos de literatura extranjera en España (19761983), Tesis de doctorado, Facultad de Filosofía y Letras, Universidad de Buenos Aires, 2014. Disponible en http://repositorio.filo.uba.ar/xmlui/ handle/filodigital/1512; Daniela Szpilbarg, "Entre el mercado y la política cultural, una mirada sociológica sobre la extraducción en Argentina. El caso del Programa Sur (2010-2012)", en El taco en la Brea, $n^{\circ}$ 5, 2017, pp. 1-16. Disponible en https://bibliotecavirtual.unl.edu.ar/publicaciones/ index.php/ElTacoenlaBrea/article/view/6640; Santiago Venturini, "Dossier La traducción editorial. Presentación", en El Taco En La Brea, $n^{\circ}$ 5, Vol.1, 2017, pp. 246-256. años veinte del siglo $X X$ de Argentina y Brasil así como construye la historia social de Borges en contraposición con la figura de genio o de escritor nato que se cristaliza con el tiempo. ${ }^{71}$

Hélène Pouliquen estudia el campo literario de Colombia mediante oposiciones y posiciones de cuatro escritores: Héctor Abad Faciolince, Philip Potdevin, Fernando Cruz Kronfly y Fernando Vallejo. ${ }^{72}$ Patricia Cabrera López estudia el vínculo entre el campo literario y la política de izquierda en México (1962-1987) en diálogo con la historia literaria oficial que deja por fuera las posiciones contestatarias..$^{73}$ Lorena Fuentes, Pierina Ferretti, Felipe Castro y Rodrigo Ortega trazan una historia de la edición independiente chilena de comienzos del siglo XXI. ${ }^{74}$ Jacinto Martínez Olvera se enfoca en tres casos que denomina editoriales "artesanales" mexicanas. ${ }^{75}$ Gustavo Sorá se enfoca en la edición de izquierda latinoamericana del siglo $X X{ }^{76}$ José de Souza Muniz compara el campo editorial brasileño y el argentino enfocado en las editoriales autodenominadas independientes. ${ }^{77}$ Ana María Agudelo Ochoa organiza un dossier sobre la edición literaria en Colombia en los siglos XX y XXI. ${ }^{78}$

Esta recopilación de trabajos no busca consolidar un ámbito de estudios. Es un ejercicio que no se constituye en un fin como el de delimitar un espacio curricular sino en un medio para dar cuenta de la riqueza de investigaciones con sensibilidad sociológica, que estudian las múltiples dimensiones del hecho literario y que estimulan la formulación de nuevos problemas y preguntas. Parten de diversas teorías y metodologías pertinentes en relación con sus respectivos objetivos y objetos de investigación.

Reflexionar sobre nuestros propios modos de producción de conocimiento abre la posibilidad de que esta especialización no

71 Sergio Miceli, Poder, sexo e letras na República Velha (estudio clínica dos anatolianos), San Pablo, Editora Perspectiva, 1977; Sergio Miceli, Ensayos porteños, Borges, el nacionalismo y las vanguardias, Buenos Aires, Editorial de la Universidad Nacional de Quilmes, 2012.

72 Hélène Pouliquen, "Algunas reflexiones acerca del campo de la novela en Colombia en la década de los años noventa del siglo XX", en Hojas universitarias, $n^{\circ} 52,2002$, pp. 178-189; Hélène Pouliquen, El campo de la novela en Colombia, una introducción, Bogotá, Instituto Caro y Cuervo, 2011.

73 Patricia Cabrera López, Una inquietud de amanecer, Literatura y política en México. 1962-1987, México, Plaza y Valdés, 2007.

74 Lorena Fuentes, Pierina Ferretti, Felipe Castro y Rodrigo Ortega, La edición independiente en Chile, Estudio e historia de la pequeña industria (2009-2014), Chile, Cooperativa Editores de La Furia, 2015.

75 Jacinto Martínez Olvera, La edición artesanal en México: tres casos, Tesis de Maestría, Universidad Autónoma Metropolitana-Xochimilco, 2016.

76 Gustavo Sorá, Editar desde la izquierda en América Latina, la agitada historia del Fondo de Cultura Económica y de Siglo XXI, Buenos Aires, Siglo XXI, 2017.

77 José De Souza Muniz Jr., Girafas e bonsais, editores 'independentes' na Argentina e no Brasil (1991-2015), Tesis de doctorado, Universidad de San Pablo, 2017

78 Ana María Agudelo Ochoa (coord.), "Dossier sobre el mundo editorial colombiano", en Estudios de literatura colombiana, ${ }^{\circ}$ 46, enero-junio de 2002, pp. 117-138. Disponible en https.//revistas.udea.edu.co/index. php/elc/issue/view/3638. 
se convierta en una "ignorancia enciclopédica", como ya advierte Alfredo Palacios, con el riesgo de reproducir aquellas "lecciones orales sin curiosidad alguna, sin ánimo de investigar, sin pasión por la búsqueda tenaz, sin laboratorios que despertaran las energías latentes, que fortalecieran el carácter, que disciplinaran la voluntad y que ejercitaran la inteligencia", sino en una producción sociológica de conocimiento vital que habilite y fomente "focos de pensamiento renovador".79

\section{Bibliografía}

Adamo, Gabriela, (comp.), La traducción en América Latina, Buenos Aires, Paidós, 2012.

Adriaensen, Brigitte; Botterweg, Meike; Steenmeijer, Maarten, y Wijnterp, Lies, (eds.), Una profunda necesidad en la ficción contemporánea, la recepción de Borges en la república mundial de las letras, Madrid, Ediciones de Iberoamericana, 2015.

Agudelo Ochoa, Ana María (coord.), "Dossier sobre el mundo editorial colombiano", en Estudios de literatura colombiana, $n^{\circ}$ 46, enero-junio de 2002, pp. 117-138. Disponible en https.// revistas.udea.edu.co/index.php/elc/issue/view/3638.

Altamirano, Carlos, y Sarlo, Beatriz, Ensayos argentinos, De Sarmiento a la vanguardia, Buenos Aires, Ariel, 1997.

Batticuore, Graciela, La Mujer Romántica, Lectoras, Autoras y Escritores En La Argentina, 1830-1870, Buenos Aires, Edhasa, 2005

Blois, Juan Pedro, "El mercado de trabajo de los sociólogos en Argentina desde la vuelta de la democracia, El caso de los graduados de la UBA", en Trabajo y Sociedad, $n^{\circ} 22$, verano de 2014, pp. 103-122. Disponible en http.//www.redalyc.org/articulo. oa?id=387334694008.

Borges, Jorge Luis. "La cultura en peligro", en Clarín, Buenos Aires, 13 de diciembre de 1984.

Bourdieu, Pierre; Chamboredon, Jean-Claude y Passeron, JeanClaude, El oficio del sociólogo, Buenos Aires, Siglo XXI, 2002 [1973].

Cabrera López, Patricia, Una inquietud de amanecer, Literatura y política en México. 1962-1987, México, Plaza y Valdés, 2007.

79 Alfredo Palacios, La universidad nueva, Buenos Aires, Gleizer, 1925, pp. 111 y 126.
Cámpora, Magdalena, "Una tradición para el lector argentino, Ediciones populares de clásicos franceses, décadas del treinta y del cuarenta", en El taco en la brea, $n^{\circ} 5$, Vol. 4, 2017, pp. 322344.

Carilla, Emilio, "Autores, libros y lectores en la literatura argentina", en Cuadernos de Humanitas, $n^{\circ} 51$, Facultad de Filosofía y Letras, Universidad Nacional de Tucumán, 1979.

Carri, Roberto, Isidro Velázquez, Formas prerrevolucionarias de la violencia, Buenos Aires, Colihue, 2001 [1968].

Castro, Marcela, "Dossier, Mujeres que hacen libros", en Mora, $\mathrm{n}^{\circ}$ 2, Vol. 7, septiembre de 2011. Disponible en http:// www.scielo.org.ar/scielo.php?script=sci_issuetoc\&pid=1853001X20110002\&lng=es\&nrm=iso.

Cerviño, Mariana, "El estudio de la literatura y el arte en las 'periferias', Algunos aportes de la perspectiva transnacional", en Apuntes de Investigación del CECYP, n 30, 2018, pp. 161-170. Disponible en http.//apuntescecyp.com.ar/index.php/apuntes/ article/view/688/528.

Cuestas, Paula, "Experiencias y encuentros entre niña/os y libros", en Horizontes - Revista de Educação, Dourados-MS, $n^{\circ} 11$, Vol. 6, 2018, pp. 181-191.

De Diego, José Luis (dir.), Editores y políticas editoriales en Argentina (1880-2010), Buenos Aires, Fondo de Cultura Económica, 2014 [2006].

De Diego, José Luis, ¿Quién de nosotros escribirá el Facundo? Intelectuales y escritores en Argentina (1970-1986), La Plata, Ediciones al margen, 2007.

De Souza Muniz, Jr. José, Girafas e bonsais, editores 'independentes' na Argentina e no Brasil (1991-2015), Tesis de doctorado, Universidad de San Pablo, 2017.

Durkheim, Émile, Las formas elementales de la vida religiosa, Buenos Aires, Editorial Schapire, 1968 [1912].

Elias, Norbert, Mozart, Sociología de un genio, Barcelona, Editorial Península, 1991.

Espósito, Fabio, La emergencia de la novela en Argentina, La prensa, los lectores y la ciudad (1880-1890), La Plata, Ediciones al margen, 2009.

Falcón, Alejandrina, Exilio y traducción, importadores argentinos de literatura extranjera en España (1976-1983), Tesis de doctorado, Facultad de Filosofía y Letras, Universidad de 
Buenos Aires, 2014. Disponible en http://repositorio.filo.uba.ar/ xmlui/handle/filodigital/1512.

Fernández, Pura, "¿Una empresa de mujeres? Editoras iberoamericanas contemporáneas", en Lectora, n² 25, 2019, pp. 11-39. Disponible en https//revistes.ub.edu/index.php/lectora/ article/view/29830.

Ford, Aníbal, 30 años después, 1973, las clases de introducción a la literatura y otros textos de la época, La Plata, Ediciones de Periodismo y Comunicación, 2005.

Fuentes, Lorena; Ferretti, Pierina; Castro, Felipe y Ortega, Rodrigo, La edición independiente en Chile, Estudio e historia de la pequeña industria (2009-2014), Chile, Cooperativa Editores de La Furia, 2015.

García Canclini, Néstor, Culturas híbridas, Estrategias para entrar y salir de la modernidad, México, Grijalbo, 1992 [1989].

Gerbaudo, Analía, Políticas de exhumación, Las clases de los críticos en la universidad argentina de la posdictadura (19841986), Santa Fe, Buenos Aires, Ediciones de la Univeridad Nacional del Litorial/Ediciones de la Universidad Nacional de General Sarmiento, 2016.

Germani, Gino, "La clase media en la Argentina con especial referencia a sus sectores urbanos", en Theo R; Crevenna (ed.), La clase media en Argentina y Uruguay, Cuatro colaboraciones, Washington, Unión Panamericana, Departamento de Asuntos culturales, Publicaciones de la oficina de Ciencias Sociales, 1950, pp. 1-33.

Gilman, Claudia, Entre la pluma y el fusil, Debates y dilemas del escritor revolucionario en América Latina, Buenos Aires, Siglo XXI, 2003.

Gramuglio, María Teresa, Nacionalismo y cosmopolitismo en la literatura argentina, Rosario, Editorial Municipal de Rosario, 2013.

Howsam, Leslie, "In My View, Women and Book History", en SHARP News, $n^{\circ}$ 4, Vol. 7, 1998, pp. 1-2. Disponible en https:// scholarworks.umass.edu/sharp_news/vol7/iss4/1.

Hoyos, Héctor, Beyond Bolaño. The Global Latin American Novel, Nueva York, Columbia University Press, 2015.

Idez, Ariel, La revista Sitio y las figuras del intelectual sobre el fin de la dictadura, Tesis de maestría, Facultad de Ciencias Sociales, Universidad de Buenos Aires, Buenos Aires, 2017.
Idez, Ariel, Literal, La vanguardia intrigante, Buenos Aires, Prometeo libros, 2010.

Kornblit, Ana Lía, "De referatos, referees y jueves", en Sociedad. Revista de la Facultad de Ciencias Sociales de la UBA, $n^{\circ} 22$, primavera de 2003, pp. 253-255. Disponible en http.//www. sociales.uba.ar/wp-content/uploads/Sociedad_22.pdf.

Kreimer, Pablo y Blanco, Alejandro, "Sociologie et démocratie? Un panorama de la discipline en Argentine entre 1983 et 2007 ", en Sociologies pratiques, $n^{\circ} 16$, Vol. 1, 2008, pp. 147-161.

Locane, Jorge, "La mediación oculta, los agentes literarios en la producción de literatura "latinoamericana" en Europa", en Iberoromania, Revista dedicada a las lenguas, literaturas y culturas de la Península lbérica y de América Latina, $n^{\circ} 85$, 2017, pp. 47-57.

Losada, Alejandro, "La Internacionalización de la literatura latinoamericana", en Cahiers du monde hispanique et lusobrésilien, Littérature et Société en Amérique latine, $n^{\circ} 42$, 1984, pp. 15-40. Disponible en https.//www.persee.fr/doc/ carav_0008-0152_1984_num_42_1_1666.

Lucena, Daniela, "Sociología del arte, Un mapa posible de su desarrollo en Argentina", en Apuntes de Investigación del CECYP, $n^{\circ}$ 30, 2018, pp. 151-160. Disponible en http:// apuntescecyp.com.ar/index.php/apuntes/article/view/687/532.

Maradei, Guadalupe, Contiendas en torno al canon, Las historias de la literatura argentina de posdictadura, Buenos Aires, Corregidor, 2020.

Marquina, Monica, Yuni, Jose, y Ferreiro, Mariela, "Generational change in the Argentine academic profession through the analysis of 'life courses'", en Studies in Higher Education, $n^{\circ} 8$, Vol. 40, 2015, pp. 1392-1405. Disponible en http.//dx.doi.org/10.1 080/03075079.2015.1060707.

Martínez Olvera, Jacinto, La edición artesanal en México, tres casos, Tesis de Maestría, Universidad Autónoma MetropolitanaXochimilco, 2016.

Martínez Zuccardi, Soledad, En busca de un campo cultura propio, Literatura, vida intelectual y revistas culturales en Tucumán (1904-1944), Buenos Aires, Corregidor, 2012.

Martínez, Ana Teresa, Pierre Bourdieu, razones y lecciones de una práctica sociológica, Del estructuralismo genético a la sociología reflexiva, Buenos Aires, Manantial, 2007.

Miceli, Sergio, Ensayos porteños, Borges, el nacionalismo y las 
vanguardias, Buenos Aires, Editorial de la Universidad Nacional de Quilmes, 2012.

Miceli, Sergio, Poder, sexo e letras na República Velha (estudio clínica dos anatolianos), San Pablo, Editora Perspectiva, 1977.

Mihal, Ivana, Ribeiro, Ana Elisa y Szpilbarg, Daniela, (coords.), "Dossier, Editoras y autorías, las mujeres en el mundo editorial Latinoamericano", en Cuadernos del Centro de Estudios en Diseño y Comunicación, $\mathrm{n}^{\circ}$ 107. Disponible en https://fido. palermo.edu/servicios_dyc/publicacionesdc/cuadernos/detalle_ publicacion.php?id_libro=835.

Moscardi, Matías, La máquina de hacer libritos, Poesía argentina y editoriales interdependientes en la década de los noventa Córdoba, Editorial Universitaria Villa María, 2019.

Moya, María Fernández, "La internacionalización del sector editorial español (1898-2010)", en X Congreso Internacional de la Asociación Española de Historia Económica, Sevilla, Universidad Pablo de Olavide Carmona, 2011.

Murray, Simone, Mixed Media, Feminist Presses and Publishing Politics, Londres y Virginia, Pluto Press, 2004.

Palacios, Alfredo, La universidad nueva, Buenos Aires, Gleizer, 1925.

Panesi, Jorge, "Política y ficción, o acerca del volverse literatura de cierta sociología argentina", en Boletín del grupo de estudios de teoría literaria, $n^{\circ}$ 4, abril de 1995, Rosario, pp. 5-13.

Pates, Giuliana, “¿Los/as jóvenes no leen? Experiencias de lecturas en booktubers", en Letras, $n^{\circ} 1$. Disponible en http:// sedici.unlp.edu.ar/bitstream/handle/10915/46664/Documento_ completo.pdf?sequence $=1$.

Pecoraro, Enrique, "La sociología nacional, las sociologías y la sociología", en Antropología, 3er mundo, Revista de ciencias sociales, $n^{\circ} 2$, Vol. 5, 1972, pp. 75-85.

Planas, Javier, Libros, lectores y sociabilidades de lectura, Una historia de los orígenes de las bibliotecas populares en la Argentina, Buenos Aires, Ampersand, 2017.

Pouliquen, Hélène, El campo de la novela en Colombia, una introducción, Bogotá, Instituto Caro y Cuervo, 2011.

Pouliquen, Hélène, "Algunas reflexiones acerca del campo de la novela en Colombia en la década de los años noventa del siglo XX", en Hojas universitarias, $n^{\circ} 52,2002$, pp. 178-189.

Prieto, Adolfo, El discurso criollista en la formación de la
Argentina moderna, Buenos Aires, Sudamericana, 1988

Prieto, Adolfo, Sociología del público argentino, Buenos Aires, Ediciones Leviatán, 1956.

Pulleiro, Adrián, Liberales, populistas y heterodoxos, Estudios sobre intelectuales, cultura y política en la Argentina reciente, Buenos Aires, Batalla de ideas, 2017.

Rama, Ángel, Transculturación narrativa en América Latina, Buenos Aires, Ediciones El andariego, 2008 [1984].

Ribeiro, Ana Elisa, "Editoriales y editoras en Brasil hoy. Dos casos contemporáneos: Chão da feira y Relicário", en Lectora, $n^{\circ} 25$, 2019, pp.227-240. Disponible en https//revistes.ub.edu/index. php/lectora/article/view/29843/0.

Rinesi, Eduardo, "Ciencias Sociales, apuntes para una discusión", en Cuadernos de la comuna, $n^{\circ} 15,1988$, pp. 9-16.

Rodríguez, Susana, A. C. (coord.), Periodismo y literatura. El campo cultural salteño del '60 al 2000, Salta, Universidad de Salta, 2007

Román, Viviana y Spadaro, María Cristina, "Mujeres en la historia de la edición argentina. ¿La edición va teniendo marca de género?", en La aljaba, segunda época, n² 23, 2019, pp. 169-189.

Rubinich, Lucas, "Las voces de los intelectuales. Hay molinos y hay gigantes", en Todavía. Pensamiento y cultura en América Latina, $n^{\circ} 27$, mayo de 2012, pp. 24-29.

Rubinich, Lucas, "Los sociólogos intelectuales, cuatro notas sobre la sociología en los años 1960", en Apuntes de Investigación del CECYP, n 4, Vol. III, junio de 1999, pp. 31-55.

Rubinich, Lucas, "Prólogo", en Adrián Pulleiro, Liberales, populistas y heterodoxos, Estudios sobre intelectuales, cultura y política en la Argentina reciente, Buenos Aires, Batalla de ideas, 2017, pp. 13-18.

Rubinich, Lucas, Indiferencia del público lector de la ciudad de Buenos Aires ante el éxito editorial del Martín Fierro (187378), Tesis de posgrado, Facultad de Ciencias Sociales, Universidad de Buenos Aires, Buenos Aires, 1982.

Rubinich, Lucas, La conformación de un clima cultural, Neoliberalismo y universidad, Buenos Aires, Libros del Rojas, 2001.

Rubinich, Lucas; y Miguel, Paula (eds.), 01 10, Creatividad, economía y cultura en la ciudad de Buenos Aires 2001-2010, 
Buenos Aires, Aurelia Rivera, 2011

Saez, Victoria, "De las pantallas al papel, Nuevos acercamientos de los jóvenes a la literatura", en El toldo de Astier, n 18, Vol. 10, 2019, pp. 42-51.

Saferstein, Ezequiel, "El "sentido práctico del editor", transformaciones y tensiones en el transformaciones y tensiones en el rol del Director Editorial de las grandes empresas en Argentina", en Prácticas de oficio; Investigación y reflexión en Ciencias Sociales, $n^{\circ} 14,2014$. Disponible en https//ides.org.ar/ publicaciones/practicasdeoficio/practicas-de-oficio-investigaciony-reflexion-en-ciencias-sociales-nro-14.

Saferstein, Ezequiel, "Las ferias de libros y sus públicos Circulación, visibilidad y desigualdades estructurales en el campo editorial", en Daniel Badenes y Verónica Stedile Lina (comps.), Estado de feria permanente, La experiencia de las editoriales independientes argentinas 2001-2020, La Plata, Club Hem, 2019.

Sánchez, Paloma, Nuevas formas de apropiación cultural juvenil, Representaciones sobre los procesos de lectura y escritura en soportes digitales, Tesis doctoral, Facultad de periodismo y comunicación social, Universidad Nacional de La Plata, 2018. Disponible en http://sedici.unlp.edu.ar/handle/10915/74969.

Sarlo, Beatriz, "Borges después de Borges", en Brigitte Adriaensen; Meike Botterweg; Maarten Steenmeijer y Lies Wijnterp, (eds.), Una profunda necesidad en la ficción contemporánea, la recepción de Borges en la república mundial de las letras, Madrid, Ediciones de Iberoamericana, 2015, pp. 31-44.

Sarlo, Beatriz, Escenas de la vida posmoderna, Intelectuales, arte y video-cultura en la Argentina, Buenos Aires, Ariel, 1994.

Schwartz, Jorge, Vanguardia y cosmopolitismo en la década del veinte, Oliverio Girondo y Oswald de Andrade, Rosario, Beatriz Viterbo, 2002 [1983].

Semán, Pablo, Bajo continuo, Exploraciones descentradas sobre cultura popular y masiva, Buenos Aires, Editorial Gorla, 2006.

Sorá, Gustavo, Editar desde la izquierda en América Latina, la agitada historia del Fondo de Cultura Económica y de Siglo XXI, Buenos Aires, Siglo XXI, 2017.

Sorá, Gustavo, Traducir El Brasil, una antropología de la circulación internacional de ideas, Buenos Aires, Libros del Zorzal, 2003.
Szpilbarg, Daniela, "Entre el mercado y la política cultural, una mirada sociológica sobre la extraducción en Argentina. El caso del Programa Sur (2010-2012), en El taco en la Brea, $n^{\circ} 5$, 2017, pp. 1-16. Disponible en https://bibliotecavirtual.unl.edu.ar/ publicaciones/index.php/ElTacoenlaBrea/article/view/6640.

Szpilbarg, Daniela, Armas cargadas de futuro, hacia una historia feminista de la edición en Argentina, en Malisia. La revista, $n^{\circ} 4$, Vol. 1, mayo de 2018, pp. 15-29.

Szpilbarg, Daniela, Cartografía argentina de la edición mundializada, Modos de hacer y pensar el libro en el siglo XXI, Buenos Aires, Tren en movimiento, 2019.

Unzué, Martín, Profesores, científicos e intelectuales, La Universidad de Buenos Aires de $\mathbf{1 9 5 5}$ a su Bicentenario, Buenos Aires, Instituto de Investigaciones Gino Germani y CLACSO, 2020.

Vanoli, Hernán, El amor por la literatura en tiempos de algoritmos. 11 hipótesis para discutir con escritores, editores, lectores, gestores y demás militantes, Buenos Aires, Siglo XXI y Crisis, 2019

Vanoli, Hernán, Por una Sociología del espacio editorial cuatro modelos de edición literaria en la Argentina del siglo $\mathbf{X X}$, Tesis de maestría, Facultad de Ciencias Sociales, Universidad de Buenos Aires, 2010.

Venturini, Santiago, "Dossier La traducción editorial. Presentación", en El Taco En La Brea, n 5, Vol. 1, 2017, pp. 246256.

Weber, Max, Ensayos sobre metodología sociológica, Buenos Aires, Amorrortu editores, 1958.

Willson, Patricia, La Constelación del Sur, Traductores y traducciones en la literatura argentina del siglo $\mathbf{X X}$, Buenos Aires, Siglo XXI, 2004.

Wortman, Ana, "Consumos de las nuevas clases medias, fragmentación de públicos en la Argentina contemporánea, Una mirada a partir de los libros", en Actas del Primer Coloquio Argentino de Estudios sobre el Libro y la Edición, La Plata, Facultad de Humanidades y Ciencias de la Educación, Universidad Nacional de La Plata, 2012, pp. 563-575. Disponible en http:// coloquiolibroyedicion.fahce.unlp.edu.ar/actas/Wortman.pdf/ view?searchterm=None.

Zanetti, Susana, La dorada garra de la lectura, Lectores y lectoras de novela en América Latina, Rosario, Beatriz Viterbo Editora, 2002. 


\section{Resumen}

Este artículo parte de la identificación de indicadores de la constitución de un ámbito de estudios sociológicos dedicados a la literatura. A partir de allí la argumentación se estructura en tres reflexiones. En primer lugar, postula la riqueza del abordaje sociológico sobre el hecho literario tanto para el conocimiento de la literatura como para la producción sociológica. En segundo lugar, el artículo reflexiona de manera crítica sobre los supuestos teóricos y el recorrido histórico que Lleva a las disciplinas a la especialización en subáreas como la de la sociología de la literatura. En tercer lugar, recopila una rica tradición de investigaciones que con sensibilidad sociológica formulan problemas de investigación relevantes sobre las múltiples dimensiones del hecho literario. Este ejercicio abre preguntas sobre nuestros modos de producción de conocimiento, sobre cómo se definen los problemas de investigación y sobre las vocaciones que definen la tarea científica.

Palabras clave: sociología de la literatura; especialización; hecho literario; producción de conocimiento.

\section{Abstract}

This article identifies indicators of the definition of an area within sociological studies dedicated to literature. The argument is divided in three lines. In the first place, the text sustains that a sociological analysis focused on the literary fact enriches our knowledge of literature as well as our understanding of social issues. Secondly, the text critically reflects upon the theoretical suppositions and history leading to the specialization and division in subareas of this discipline. In third place, this article compiles a rich tradition of works that with a sociological viewpoint outline relevant research problems on the multiple dimensions of the literary fact. This exercise raises questions on our ways of producing knowledge, on the ways we define research problems, and on the vocation of science.

Keywords: Sociology of Literature; Specialization; Literary Fact; Production of Knowledge

Recibido: 5-8-2020

Aceptado: 22-9-2020 